\title{
FATHER OF THE BOTTOM: TOWARDS A CRITIQUE OF SAME-SEX MARRIAGE
}

\author{
By Marcos Moldes
}

On July 20th, 2005, the federal government of Canada passed Bill C-38, the Civil Marriage Act, which changed the legal definition of marriage as the lawful union of two persons to the exclusion of all others. This changed the federal legislation from defining marriage as a union between a man and a woman and broadened the legal definition to include same-sex couples. Canadians for Equal Marriage (CEM), one of the principal advocacy organizations, lauded the change in legislation as an important move towards equality for same-sex individuals. The organization's advocacy work leading up to the vote in the House of Commons, along with their public media campaigns, reinforced the position that saw the inclusion of queer unions into federal definitions of marriage as an important moment for the queer rights movement. The discourse that surrounded this debate leading up to and after July $20^{\text {th }}$ framed marriage as the cornerstone of queer rights and equality; yet, it lacked any sort of critique about the broader social and political implications for queer identity and the queer rights movement. Conflating marriage with equality, CEM’s discourse around gay marriage lacked any critique of how inclusion into state-legislated familial structures could impact broader discourses of queer identity. Instead, the majority of articles focused on how queer marriage was obligatory and called on all members of the queer community to embrace and organize politically around the issue of marriage. This discourse suggests the recognition of same sex unions is indicative of a broader social equality. However, it must be asked whether this assimilation into a heterosexual/heteronormative framework ensures real equality or merely the assimilation of queer identity through state-mediated kinship structures ${ }^{1}$. Although gay marriage is a tool for 
enabling the inclusion of same-sex partners into benefits packages, tax breaks and other federally legislated benefits, the language used by gay marriage advocates problematically links concepts of equal rights to marriage without questioning or critiquing the concept of state-mediated kinship structures. Looking at the media campaign around this issue, and how it linked the attaining of rights to legalizing marriage it must be asked whether this would create real social acceptance, or whether the same-sex marriage debate is an in actuality just an attempt to normalize queer relationships into a larger heteronormative framework.

Drawing on the work of Judith Butler's critique of state-mediated kinship, I provide a critique of same-sex marriage as an ideologically heterosexual construction and illustrate how its inclusion in federal legislation imposes normative and hegemonic relationship values onto queer identity. This is not to say that identity is determined by legislation but rather an acknowledgement of how same-sex marriage advocacy often relies on constructing an image of gayness that is predicated on values and ideals that espouse a traditional conception of family structures. These values privilege monogamy, heteronormative relations of power and a discourse of normalization, which limits the possibilities for creating alternative relationship structures in the queer community. This normalization of queer relationships creates a mythology that suggests that, by accepting the social values of mainstream society, queer communities will be perceived as acceptable. Problematically, gay-marriage proponents fail to recognize that while fighting for queer equality is important, one could argue that it may be difficult to do through an appropriation of heterosexual kinship values. Nor does assimilation into state-mediated heteronormative institutions allow for queer identity to challenge mainstream conceptions of family and kinship structures. If this is true, gay marriage has less to do with equality and more to do with assimilation. I intend to explore the ways a discourse of equality may mask a 
discourse of conformity in queer marriage, and the potential ramifications of this.

Marriage has a long history as a legal and state-mediated institution. Feminist criticisms of marriage contend that marriage has been a harmful institution to women as citizens. Marriage, according to feminist thinking, reinforces inequality, gender roles/hierarchy and male dominated power (Josephson, 270). Stemming from the sexist discourse that polices women’s lives, marriage is seen as a tool of dominant discourses that dictates and specifies the validity (or invalidity) of familial and sexual relationships in the eyes of the state. Through legislation that criminalized behaviour outside of the accepted definitions of sexual expression and marriage, the state constructed the acceptable family structure and turned it into a prerequisite for citizenship and national belonging (Brandzel, 172).

While the image and exact specifications of this family structure has changed slightly over the course of the last century, North American cultural conceptions of family structures have not changed dramatically since these structures remain a private and heteronormative institution. Although marriage and family structures are normalized and naturalized, critics have noted that the laws and regulations that surround marriage are extremely convoluted. The regulation of the family as a social unit involves not only gendered and racialized histories, but also involves a number of considerations, exceptions and special circumstances in areas of divorce, property, estate and tax law (Brandzel, 181). This immense legal structure, constructed in order to protect and privilege marriage, can be seen as evidence that marriage is neither normal nor natural but is instead a cultural construction used to exclude marginalized individuals from gaining access to privilege. Polyamorous relationships, for example, are rarely discussed without being described as somehow pathological. Thus, marriage is constructed and performed as the foundation for the family structure and is, in turn, portrayed as the building block of 
society. The reality of how marriage and family structures operate is indeed the reverse; society is constructed in order to privilege marriage as a social and cultural phenomenon that has come to dominate discourses of sexuality, sexual expression, child-rearing and social organization.

Bearing this in mind, it is necessary to think of the inclusion of same-sex couples into the definition of marriage not as an act of equality, but instead as the assimilation of queer sexual relationships into normative social networks. Marriage and conceptions of the family function as a 'moral' unit, a way of organizing and conceptualizing human relationships into a hierarchical structure within a larger social context (Colier, Rosaldo \& Yanagisako, 76). Therefore, the family unit is thought of as the natural and fundamental system of kinship organization, yet there exists a multitude of family structures and variations in familial systems throughout the world, particularly outside of western ontologies. Families are therefore not a 'natural' organization but, rather, mediated and constructed to hold a privileged status based on biological reproduction and benefiting from state-sanctioned institutions which privilege this unit in specific ways through legislation (Josephson, 272). We are encouraged to think of families not as ideological units but as naturally occurring units when, in actuality, Western conceptions of the family are full of inherent contradictory positions. Colier, Rosaldo \& Yanagisako (1997) identify these contradictions and argue that while the family is seen as the antithesis of market relations and the last bastion against the state, our conception of the family as a kinship structure relies heavily on both the state and the market in order to survive (78). The debate in favour of same-sex marriage is, however, not discussed in terms of economic or state-mediated rights and privileges but uses the rhetoric of equal rights and equality in order to garner public support. CEM's activist work around marriage, for example, did not engage with marriage as an economic contract but instead chose to reinforce marriage as an expression of a 'responsible' sexual relationship. Advocates in 
favour of the inclusion of same-sex couples into legal definitions of marriage do not engage in the possibility of deconstructing marriage and reconstructing alternative family structures. The debate around same-sex marriage had less to do with equal rights (or the imagined possibility of equal rights in a capitalist system) and more to do with economic and state-mandated benefits for people who subscribe to cultural norms of sexual and social organization.

On June $30^{\text {th }}$ 2005, CEM released a press release entitled “Gay Marriage Rights: The Canadian thing to do" by Alex Munter, CEM’s co-ordinator and the organization's national spokesperson which stated:

"In a generation, Canadians will look back on a time when lesbian and gay people were denied full citizenship, just as we look back on the days when women or Aboriginal people could not vote or times when Canadian citizens were interned because of ethnic origin. We will talk about these days and this battle. We will be proud, as Canadians, that we rejected rejection, that we ended exclusion, that we said to [gay, lesbian, bisexual and trans] people: there are no second-class Canadians, lesbian and gay people are full members of the community, without caveat or exceptions. We will long remember this proud day.”

Munter's statement is indicative of some of the problems that arise when examining the discourse of same-sex marriage debates. Here, issues become over-simplified and romanticized in order to give the discourse a certain air of legitimacy. By drawing on social justice norms deeply entrenched in the mainstream (such as the elimination of racism or sexism), CEM attempts to draw on allies in order to incorporate the queer body in the language of racialminority struggle. Here, the struggle for same-sex marriage is compared to the civil rights movements for visible minorities and native Canadians, yet drawing comparisons to de- 
contextualized and de-historicized activist movements does not recognize the problematic nature of comparing ethnic visible minorities to a largely middle-class white activist movement.

Munter's statement makes very broad connections to the discrimination faced by immigrant and aboriginal communities and sexist practices of discrimination. His statement completely disregards the very real discourses of sexism and racism that continue to exist in spite of (and in some cases thanks to) state-mediated legislation. By attempting to draw comparisons on the basis of shared social exclusion, Munter's statement collapses the still ongoing, brutal systemic racism faced by visible minorities into an imaginary barbaric past with no connection to the current experiences of racism or sexism. This simplifies social issues of homophobia, racism, and sexism into mere problems that can be solved through state legislation, citizenship and conformity to mainstream ontologies and epistemes. Although conformity is not in itself a negative act it is the privileging of marriage over other relationships through legislation that is problematic.

CEM's press release helps to solidify the link between citizenship and marriage in dangerous ways, thus reinforcing conceptions of heteronormative citizenship in the queer community without discussing the possibility for a queer alternative. While it may seem ridiculous to critique an organization that advocates for the inclusion of queers into mainstream institutions, there is a distinct danger in the adoption of and conformity to mainstream values, most notably the risk of assimilation into the mainstream and the coerced adoption of heteronormative ontologies.

This discourse of conformity carries with it serious implications for queer identity as it relies on queers conforming to mainstream politics in order to gain full citizenship in traditional society. Johnson (2002) argues that access to the rights and entitlements of citizenship often 
involves a 'politics of passing', a practice that allows governments to assert heterosexual privilege by dictating what sort of 'good' behaviour queers must conform to. Conformity gives those who are willing to assimilate into mainstream culture the rewards of citizenship and thus creates a code of expectation. This also creates a method of encouraging what Johnson identifies as good homosexual behaviour, that is a homosexual subject that still reinforces heteronormative conceptions of citizenship by assimilating and indeed striving to operate within the very structures of exclusion (Johnson, 320). By dictating a discourse of conformity to heteronormative values, queer identities are forced to perform heterosexuality via self-regulation and policing according to the rules of a dominant society (328). This raises some serious considerations in regards to the question of whether or not same-sex marriage is liberating. If same-sex marriage is merely the inclusion into a privileged institution by embracing and indeed performing dominant ideologies, then Bill C-38 is merely state-sponsored assimilation.

Munter's press release is indicative of the language CEM uses in order to push for same sex rights, a language that evokes images of subjugated queers denied the benefits of marriage fighting for inclusion into the larger mainstream institution of marriage. This strategy relies on creating images of conformist gay and lesbian individuals who simply wanted to gain access to a heteronormative institution, to "fit in" and comply with mainstream conceptions of a relationship. Rather than using the discourse of homosexual/queer in opposition to the discourse of heterosexuality, CEM creates a discourse that incorporates the Other as willing to pass as heterosexual citizens by embracing heteronormative institutions and legislation. The queer Other is being incorporated into the larger hegemonic mainstream in various ways; by advocating for inclusion into mainstream heteronormative marriage structures, queers are "passing” as good heterosexual citizens (Johnson, 330). This strategy is incredibly troubling as it relies on notions 
that frame the same-sex marriage debate not as an opportunity to create alternative kinship and family structures, but instead attempts to contextualize inclusion as an opportunity to reinforce marriage as the state tool of citizenship, clearly demarcating who belongs and who does not. Gamson (1995) notes that this method of attaining rights is an incredibly passive strategy, as it attempts to be non-threatening and conformist in relation to dominant (heterosexual) values (396). By embracing marriage as an important institution and advocating for inclusion within the Marriage Act, proponents are simultaneously and paradoxically performing a disservice to queer rights as they advocate conformity to existing heteronormative frameworks.

Moreover, CEM's attempts to create a discourse of queer conformity are in direct conflict with the long history of queer activism that prides itself on difference from the mainstream. Queer asserts itself, as Gamson (1995) put it, as “an in-your face difference, with an edge of defiant separatism... Queer does not so much rebel against outsider status as revel in it” (395). Yet CEM’s image of queer identity has no mention of Gamson’s “in your face” difference; it instead creates a language of subordinate identities that seek to privilege and attempt to perform dominant identities (Johnson, 227-28). CEM's image of queerness is not one of difference nor does it engage with how queer identity has embraced its marginality as a means to critique mainstream heteronormative values. In a press statement released on June $28^{\text {th }} 2005$ CEM attempts to link queers to the mainstream:

But the biggest champions are the millions of individual lesbian, gay, bisexual and transgender people who live their lives on a daily basis with open-ness and honesty. It is the simple act of simply being that has made today's victory possible. Because of individuals' commitment to live their lives matter-of-factly they have demonstrated this reality: we are your brothers and sisters, neighbours, friends, co-workers. 
Indeed CEM's image of queerness, as modelled above, is indicative of Johnson's heteronormative passing: the 'good' homosexuals are prepared to embrace heterosexual citizenship and are clearly distinguished from the 'bad' gays and lesbians who are not (Johnson, 330). Through the deployment of the discourse that queers are the brothers, sisters, co-workers of heterosexuals, CEM manages to normalize and create a heteronormative homosexuality that merely produces fixed dichotomous identity categories like "gay” and “lesbian” (Johnson, 329). This move to inoculate queer discourses from an activist agenda betrays the very foundation of queer identity since, rather than challenge fixed identity categories, CEM uses gay bodies to solidify them. The most distinctive form of queerness is erased from the debate of same-sex marriage as queer activism sought to contest concrete labels like "man”, “woman”, "sexual minority" and "gay and lesbian” (Gamson, 390).

Likewise, CEM's language is full of statements that link marriage to citizenship and nationhood. In this sense, citizenship, nationhood and rights become intertwined and mutually interdependent. That is, because citizenship relies on marriage as a site of reproduction and normativity, marriage becomes the method by which discourses of "good citizens" are produced and disseminated into society. By attaching state-sponsored privileges to conceptions of marriage and partnership, the state is ensuring a properly heterosexual, gendered and racialized citizenry (Brandzel, 177). Citizenship in the Canadian polity includes the right to marry as one of its privileges. Civil marriage is a state-mediated conception defined by the Marriage Act that states: "Marriage, for civil purposes, is the lawful union of two persons to the exclusion of all others" (Civil Marriage Act, 2005, 5). The inclusion of same-sex couples into this act brings into line queer bodies that previously were not mentioned in the marriage act.

As such, the primary question becomes one of citizenship and, more specifically, what 
the function of citizenship is in reference to marriage. If citizenship gives the privilege of marriage solely to its own citizens under fairly strict conditions, is it not simply another form of social exclusion aimed at the sexual, racial and underclass? Brandzel (2005) discusses how citizenship's normative functions are articulated through marriage as a state-sponsored institution that privileges very specific relationships above others (176). By including monogamous queer marriage into the Marriage Act, citizenship manages to present itself as a universal and inclusionary construct when, in reality, it merely assimilates relationships that are fairly normative to begin with. However, long-term monogamous queer couples do not necessarily represent the entire breadth of queer identity. Rather, they are merely a small fraction of an imagined community of queers. Marriage law is one of the primary sites wherein the production of normative citizenship can be created: it is a key mechanism of the state for the creation of a citizenry that has been shaped through heteronormative and monogamous values (Brandzel, 177).

Yet the language of universality and normativity can be seen in statements issued by Canadian’s for Equal Marriage:

We believe strongly in a Canada where no-one faces discrimination because of personal characteristics such as their race, their religion, or their sexual orientation. Once it becomes acceptable to discriminate against any vulnerable group, no Canadian is safe. Same-sex couples have the same basic right as anyone else to affirm their love and commitment through marriage.

The focus on marriage by queer activists remains incredibly contentious. By demanding inclusion into mainstream institutions, groups like CEM invariably reify and assert the importance of marriage rather than providing a critique and deconstruction of it (Brandzel 189). 
Furthermore, the reification of marriage does not address the systemic discrimination of queer physical expression. While some queer relationships have now been normalized and absorbed into state-sponsored kinship structures, age of consent laws continue to differ for those who participate in anal sex ${ }^{2}$ Yet CEM makes no mention of this discrimination and affirms that inclusion in marriage is the path to full citizenship and the end of discrimination. While queer adults have been given permission by the state to participate in a normative institution, the physical expression of sexuality by queer youth has been criminalized and forbidden through the legislation of sexual morality laws. This sort of discrimination is exactly what Brandzel and other queer theorists forewarned.

While CEM's intentions of equality can be lauded for their good intentions, they go about the fight for queer rights in an almost counter-productive manner. It is true that same-sex marriage advocates have critiqued the male/female and homosexual/heterosexual binaries latent in marriage, but they have not attempted to undermine the sanctity of the domestic couple (Brandzel, 194). Rather than fighting from within the margins, a site that has given queer identity a unique position to critique normative state ideology and heteronormativity, groups like CEM advocate for social inclusion by imitating heteronormative values. Similarity to the mainstream is not enough to guarantee the rights of all queers, especially those who choose not to assimilate or conform to heteronormative values and ideals. Moreover, relationships that model themselves on the basis of monogamous heterosexual marriages affirm an implied notion of heteronormativity. In other words, same-sex marriage may not be heterosexual in a biological sense, but it continues to embrace heteronormative values in a cultural sense

By using terms associated with normative institutions like marriage, queers are mirroring the behaviour and practices of dominant ideology that help to assimilate queer relationships into 
pre-existing structures. This is encouraged since it successfully incorporates a community that previously bore no resemblance to the mainstream into an intelligible discourse. Married gay couples are, to the heterosexual subject, 'married, just like us'. Thus, this is not an equal rights movement so much as a carrot-on-a-stick approach to assimilation. Same-sex marriage has not opened up and challenged the institution of marriage to change into a broader and more inclusive institution. Rather, it has merely increased the number of 'beds' that can be approved by the state as model citizens (Brandzel, 195). While rights granted on the basis of similarity help to provide order and stability, they do not assure the inherent rights of an individual insomuch as they help to assimilate the Other into mainstream institutions. Indeed the most prominent arguments for marriage merely respond to the desire to seem not different from mainstream heterosexuals. These non-normative relationships remain a space for queer identity to continue in its function as a critique of the mainstream. That is, they operate outside of mainstream intelligibility and they cannot be state-sanctioned because of their inherent contradictions or violations of dominant codes and norms.

By defying normative institutions and pre-existing structures of kinship in society, queers can retain their power as outsiders, thus enabling queer activists to continue to demand alternatives to assimilationist discourses and attempts at normalization. They operate not only as an identity category for those on the margin but also as an example of what an alternative kinship structure may look like. Dominant kinship structures function not because they are necessarily better or more efficient than other kinship systems, but because cultural norms and mores place higher value and assign specific rights and privileges to the system favored by dominant forces. The debate around gay marriage therefore implicates not just heterosexuals, but a plethora of kinship structures with the question of what relationships should be mediated by the state 
(Butler, 17). By demanding official recognition, same-sex marriage activists have demanded inclusion but have also inadvertently led critics to question how kinship structures, and state recognition and involvement in conceptions of family, effect the possibility for alternatives.

Butler argues that the state becomes the vehicle for delivering recognition and legitimacy to specific kinds of relationships which turn them into publicly-mediated and legitimated public sex (23). Marriage demands public recognition universally wherein rights can no longer be questioned or contested and everyone must respect and defer to the rights of the married partner (Butler, 23). With this sort of power associated with marriage and state recognition it becomes obvious that a wide spectrum of relationships and kinship structures will attempt to gain state recognition in order to legitimate their desires and become culturally acceptable.

As normalized queer relations move into a legitimized space through the lens of statemediation, non-normative relations continue to be isolated and cast out from the polity of Canadian society. Whether or not these relations will be recognized by the state and society is irrelevant so long as kinship structures require external recognition in order to be considered relevant or fruitful. For queers who seek the rights and benefits associated with legal standing and state involvement, the issue that needs to be dealt with is whether or not their kinship structure is implicated in the social exclusion and alienation of other queer ontologies. This raises very important questions for the future of queer theory and the queer identity project as divisions along assimilationist lines begin to arise and cause animosity between groups of people previously united under one banner. Perhaps then there is a certain inevitability in regards to same-sex marriage for some queers as the desire for recognition and state-granted benefits become more and more tempting. Non-normative queer single people or those who represent inherent contradictions will remain socially isolated and excluded from participating in state 
legislated relationships not because their desires are illegitimate, but because as their desires are too complex and difficult for mainstream discourses of desire and sexuality to comprehend or try to unpack. By normalizing and mediating monogamous queer couples, the institution of marriage has not been opened up and reformed as an institution of equality, nor has gay marriage sparked a debate about state involvement in kinship structures. The only difference between marriage structures before the passage of Bill C-38 and afterwards is a larger amount of regulated relationships. 


\section{Endnotes}

1. I am drawing on Butler's (2004) definition of kinship, which she defines as "a set of practices that institutes relationships of various kinds which negotiate the reproduction of life and the demands of death... kinship practices will be those that emerge to address fundamental forms of human dependency, which may include birth, child rearing, relations of emotional dependency and support, generational ties, illness, dying, and death.” (102-103).

2. Section 159 of the Criminal Code of Canada States: Every person who engages in an act of anal intercourse is guilty of an indictable offence and liable to imprisonment for a term not exceeding ten years or is guilty of an offence punishable on summary conviction. Exception (2) Subsection (1) does not apply to any act engaged in, in private, between(a) husband and wife, or(b) any two persons, each of whom is eighteen years of age or more,both of whom consent to the act. 


\section{Bibliography}

Auchmuty, Rosemary. "Same-Sex Marriage Revived: Feminist Critique and Legal Strategy.” Feminism and Psychology 14.1 (2004): 101-126.

Brandzel, Amy L. “Queering Citizenship? Same Sex Marriage and the State.” Journal of Lesbian and Gay Studies 11.2 (2005): 171-204

Bevacqua, Maria. “Feminist Theory and the Question of Gay and Lesbian Marriage.” Feminism and Psychology 14.1 (2004): 36-40

Butler, Judith. Antigone’s Claim: Kinship Between Life and Death. New York: Columbia University Press, 2000.

Butler, Judith. “Is Kinship Always Already Heterosexual?” Differences: A Journal of Feminist Cultural Studies." 15:1 (2002): 14-44

Canadians For Equal Marriage. “AFTER THE VOTE: CEM SPEAKS.” 2005. http://www.equal-marriage.ca/resource.php?id=464. April 222007.

Canadians For Equal Marriage. “Senate approves same-sex bill, CP.” 2005. http://www.equalmarriage.ca/resource.php?id=475 April 222007.

Canadians For Equal Marriage. “C-38 passes second reading in Senate 43-12.” 2005. 
http://www.equal-marriage.ca/resource.php?id=471 April 222007.

Collier, Jane, Rosaldo, Michelle Z, Yanagisako, Sylvia. “Is There a Family?” In R. Lancaster \& M. di Leonardo (Eds) The Gender/Sexuality Reader. New York: Routledge, 1997.

Gamson, Joshua. “Must Identity Movements Self-Destruct? A Queer Dilemma.” Social Problems 42:2 (1995): 390-407.

Government of Canada. “Civil Marriage Act.” Ottawa, Ontario: Department of Justice Website. 2005. http://www.justice.gc.ca/en/news/nr/2005/doc_31376.html April 192007.

Johnson, Carol. "Heteronormative Citizenship and the Politics of Passing." Sexualities 5:3 (2002): 317-336.

Johnson, Carol. "Heteronormative Citizenship: The Howard Government’s Views on Gay and Lesbian Issues.” Australian Journal of Political Science 38:1 (2003): 45-62.

Josephson, Jyl. “Citizenship, Same-Sex Marriage, and Feminist Critiques of Marriage.” Perspectives on Politics 3:2 (2005): 269-284. 